\title{
Article \\ Human Amniotic Epithelial Cells as a Tool to Investigate the Effects of Cyanidin 3-O-Glucoside on Cell Differentiation
}

\author{
Shinya Takahashi ${ }^{1,2,3}$, Farhana Ferdousi ${ }^{1,2,3}$, , Yun-Wen Zheng ${ }^{3,4}$, Tatsuya Oda ${ }^{3,4}$ and Hiroko Isoda ${ }^{1,2,3, *}$ \\ 1 Faculty of Life and Environmental Sciences, University of Tsukuba, Tsukuba 305-8572, Japan; \\ takahashi.shinya.fp@u.tsukuba.ac.jp (S.T.); ferdousi.farhana.fn@u.tsukuba.ac.jp (F.F.) \\ 2 Alliance for Research on the Mediterranean and North Africa (ARENA), University of Tsukuba, \\ Tsukuba 305-8572, Japan \\ 3 Open Innovation Laboratory for Food and Medicinal Resource Engineering (FoodMed-OIL), AIST-University \\ of Tsukuba, Tsukuba 305-8565, Japan; ywzheng@md.tsukuba.ac.jp (Y.-W.Z.); tatoda@md.tsukuba.ac.jp (T.O.) \\ 4 Department of Gastrointestinal and Hepato-Biliary-Pancreatic Surgery, Faculty of Medicine, \\ University of Tsukuba, Tsukuba 305-8575, Japan \\ * Correspondence: isoda.hiroko.ga@u.tsukuba.ac.jp
}

check for updates

Citation: Takahashi, S.; Ferdousi, F.; Zheng, Y.-W.; Oda, T.; Isoda, H. Human Amniotic Epithelial Cells as a Tool to Investigate the Effects of Cyanidin 3-O-Glucoside on Cell Differentiation. Int. J. Mol. Sci. 2021, 22, 3768. https://doi.org/10.3390/ ijms22073768

Academic Editors: John Lucocq and Ignazio Barbagallo

Received: 24 February 2021

Accepted: 1 April 2021

Published: 5 April 2021

Publisher's Note: MDPI stays neutra with regard to jurisdictional claims in published maps and institutional affiliations.

Copyright: (C) 2021 by the authors Licensee MDPI, Basel, Switzerland. This article is an open access article distributed under the terms and conditions of the Creative Commons Attribution (CC BY) license (https:// creativecommons.org/licenses/by/ $4.0 /)$.

\begin{abstract}
Cyanidin, a kind of anthocyanin, has been reported to have chemotherapeutic activities in humans. Human amniotic epithelial cells (hAECs) are considered a potential source of pluripotent stem cells. hAECs have been used as a novel tool in regenerative cellular therapy and cell differentiation studies. In this study, to explore the effects of cyanidin-3-O-glucoside (Cy3G) on hAECs and their mechanisms, we investigated the transcriptomic changes in the Cy3G-treated cells using microarray analysis. Among the differentially expressed genes (Fold change $>1.1$; $p$-value $<0.05$ ), 109 genes were upregulated and 232 were downregulated. Ratios of upregulated and downregulated genes were $0.22 \%$ and $0.47 \%$ of the total expressed genes, respectively. Next, we explored the enriched gene ontology, i.e., the biological process, molecular function, and cellular component of the $37 \mathrm{upregu}$ lated ( $>1.3$-fold change) and 124 downregulated ( $<1.3$-fold change) genes. Significantly enriched biological processes by the upregulated genes included "response to muscle activity," and the genes involved in this gene ontology (GO) were Metrnl and SRD5A1, which function in the adipocyte. On the other hand, the cell cycle biological process was significantly enriched by the downregulated genes, including some from the SMC gene family. An adipogenesis-associated gene DDX6 was also included in the cell cycle biological process. Thus, our findings suggest the prospects of Cy3G in modulating adipocyte differentiation in hAECs.
\end{abstract}

Keywords: amniotic epithelial cells; cyanidin-3-O-glucoside; global gene expression; cell differentiation; adipocyte

\section{Introduction}

In recent years, demands in foods rich in phytochemicals have increased [1]. Based on considerable epidemiological evidence, the presence of polyphenols has been proven to promote health and diminish the risk of various diseases such as cancers and cardiovascular diseases, etc. [2,3]. Polyphenols are contained in various vegetables and fruits [4]. Diets rich in polyphenols lead to the reduction of risks of several diseases $[5,6]$. To investigate the unknown functions of several phytochemicals beneficial to human health, employment of high-throughput systems based on mammalian cells is one of the best ways.

Human amniotic epithelial cells (hAECs) are considered one of the novel sources of pluripotent stem cells (PSCs). In recent years, growing attention has been given to the use of perinatal stem cells such as hAECs in the field of regenerative cellular therapy and cell differentiation studies. hAECs have some advantages over other PSCs in that they are isolated from discarded term placenta, which is a medical waste product and have similar pluripotent and multipoint properties of stem cells [7]. Therefore, hAECs are suitable 
stem cell sources with therapeutic applications. Although the effects of plant-derived compounds are extensively studied in PSCs and adult stem cells, studies on hAECs using natural compounds are very scarce. Recently, we have reported that verbenalin, a kind of phytochemical, has exerted therapeutic potential for Alzheimer's disease in hAECs [8]. Microarray gene expression profiling showed that rosmarinic acid- and isorhamnetintreated hAECs exerted neuronal and hepatic-lineage specific differentiation potential respectively $[9,10]$. A caffeoylquinic acid derivative, namely 3,4,5-Tri-O-Caffeoylquinic Acid, has also enhanced neural and pigment cell differentiation in hAECs [11]. Therefore, hAECs can be used to explore novel functions of natural compounds. Moreover, priming of hAECs with natural compounds may enhance their differentiation direction towards expected cell lineage; in addition, pretreatment with polyphenols may improve the cell's functional activities. In this regard, we have investigated the effect of cyanidin on gene expression profiling of hAECs.

Anthocyanins are water-soluble and glycosylated forms of blue, red, or purple-colored pigments found in fruits and vegetables, such as berries, grapes, some tropical fruits as well as red to purplish blue-colored leafy vegetables, colored wheat grains, and roots [12]. Anthocyanins possess anti-inflammatory, antioxidant, antidiabetic, anticancer, antiobesity, and cardioprotective effects [13]. Cyanidin, one of the anthocyanins, has a flavone skeleton with glucoside and is widely distributed in several vegetables and fruits, red leaf lettuce, black soybean, blackberries, and grapes $[14,15]$. Several kinds of cyanidin have been reported to have chemotherapeutic activities in humans. Cyanidin-3-O- $\beta$-glucopyranoside is known to induce apoptosis in T-lymphoblastoid and differentiation in HL-60 promyelocytic cells $[16,17]$. Cyanidin-3-O-glucoside (Cy3G) is the major anthocyanin found in most plants and confers a red hue to fruits [18]. Cy3G exerts high antioxidant activity [18]. It is also reported to enhance exercise performance by developing beige fat cells in mice $[19,20]$. In cell-based research, Cy3G treatment inhibited interleukin-6 production, an inflammatory mediator, in adipose stem cells [21]. There are a few reports on the effects of Cy3G on differentiation promotion of stem cells. In osteoclasts, cyanidin has dual effects on RANKL-induced osteoclastogenesis, differentiation, and fusion [22]. One study has reported chondrogenesis-stimulating effects of cyanidin on adipose tissue derived-human mesenchymal stem cells (MSCs) [23]. Cyanidin treatment also inhibited chondrogenic and hypertrophic differentiation of MSCs via decreasing autophagic activity [24]. However, studies on the effects of cyanidin on stem cell differentiation are still limited, and there is no report on this compound's effect on hAECs. In this study, we investigated the transcriptomic changes in the Cy3G-treated hAECs to explore its effects and probable mechanism on hAECs. From our results, we can anticipate the possibilities of adipocyte differentiation-inducing effects of Cy3G in hAECs.

\section{Results}

\subsection{Characteristics of Gene Expression Profiling in hAECs}

After seven days of Cy3G treatment, a total of 341 genes were differentially expressed, having fold change $>1.1$ and $p$-value $<0.05$ compared to untreated control. Among them, 109 genes were upregulated and 232 were downregulated. Ratios of upregulated and downregulated differentially expressed genes (DEGs) were $0.22 \%$ and $0.47 \%$ of total expressed genes, respectively (Figure 1A). 
A

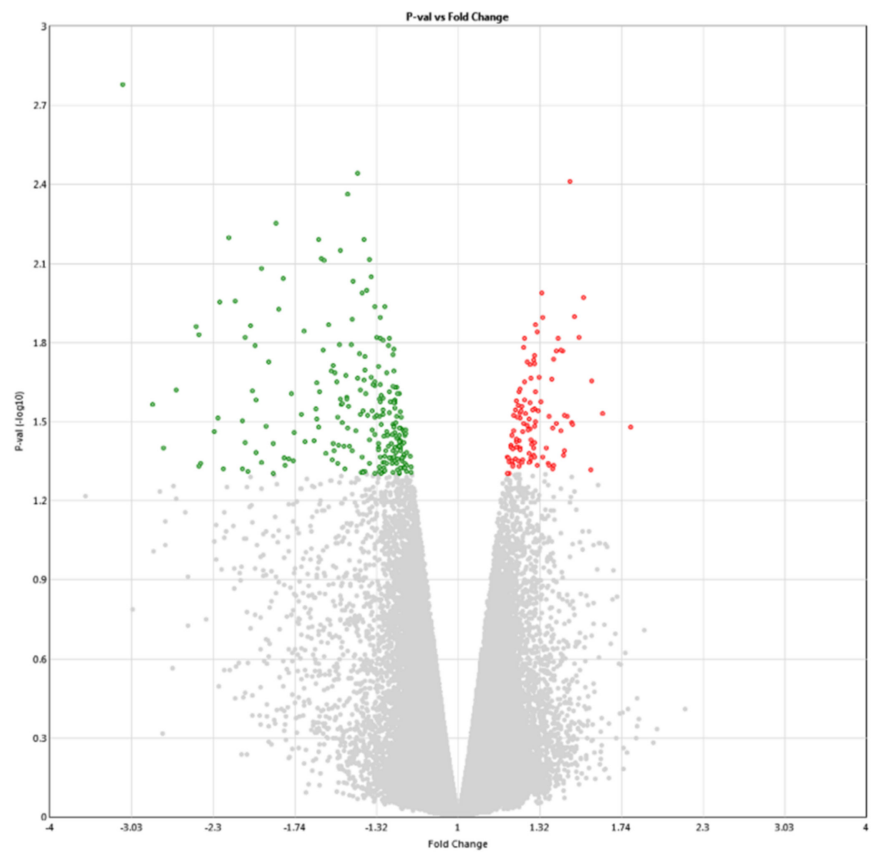

B

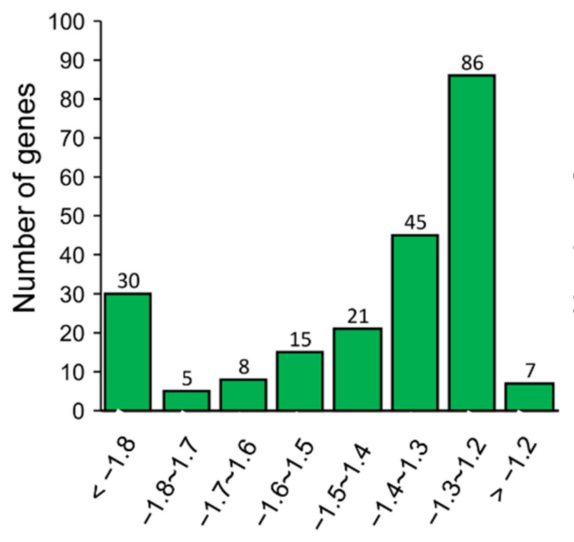

Fold change

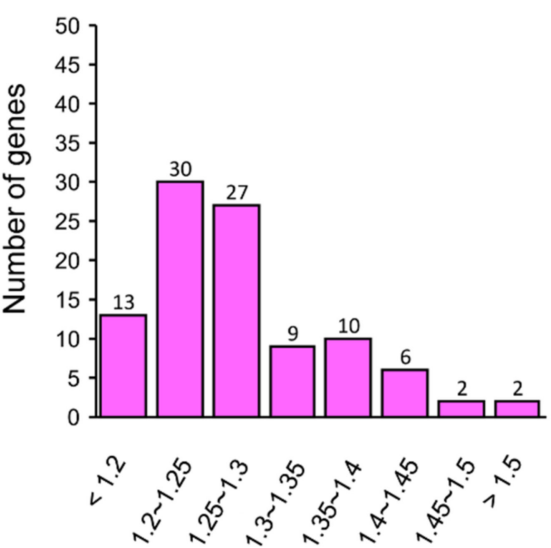

Fold change

Figure 1. Characterization of gene expression profiles in human amniotic epithelial cells (hAECs) with or without cyanidin-3-O-glucoside (Cy3G) (A) Volcano plot displaying differentially expressed genes (DEGs) between Cy3G-treated and untreated hAECs on day 7. The vertical axis corresponds to $-\log 10 p$-value of the ANOVA $p$-values, and the horizontal axis displays linear fold change. The red dots represent the upregulated genes, and the green dots represent the downregulated genes. (B) distribution of fold changes of downregulated genes (left) and upregulated genes (right) in Cy3G-treated hAECs.

\subsection{Changes of Gene Expression in Cy3G-Treated hAECs}

Five upregulated genes showed changes in the expression more than 1.45-fold (Table 1). To know the detailed features of their encoded proteins, we checked their function in the UniProt database (https: / / www.uniprot.org/, accessed on 16 April 2020). 
Table 1. List of upregulated genes with fold change $>1.3$ compared to control group.

\begin{tabular}{|c|c|c|c|}
\hline Gene Symbol & Description & Fold Change & $p$-Value \\
\hline FN3KRP & fructosamine 3 kinase-related protein & 1.57 & 0.048 \\
\hline METRNL & meteorin-like protein & 1.51 & 0.0152 \\
\hline$R A B 6 A$ & RAB6A, member RAS oncogene family & 1.47 & 0.0319 \\
\hline PSMB8 & proteasome subunit beta 8 & 1.46 & 0.0039 \\
\hline DCTN4 & dynactin $4(\mathrm{p} 62)$ & 1.45 & 0.0302 \\
\hline DCAF5 & DDB1 and CUL4 associated factor 5 & 1.43 & 0.0171 \\
\hline NR1H2 & $\begin{array}{c}\text { nuclear receptor subfamily } 1 \text {, group } \mathrm{H}, \\
\text { member } 2\end{array}$ & 1.43 & 0.0409 \\
\hline RAPGEF6 & $\begin{array}{l}\text { Rap guanine nucleotide exchange factor } 6 \\
\text { steroid-5-alpha-reductase, alpha }\end{array}$ & 1.43 & 0.0423 \\
\hline SRD5A1 & $\begin{array}{c}\text { polypeptide } 1 \text { (3-oxo-5 alpha-steroid delta } \\
\text { 4-dehydrogenase alpha } 1 \text { ) }\end{array}$ & 1.43 & 0.0298 \\
\hline ANKFY1 & $\begin{array}{l}\text { ankyrin repeat and FYVE domain } \\
\text { containing } 1\end{array}$ & 1.42 & 0.0343 \\
\hline NPTN & neuroplastin & 1.4 & 0.032 \\
\hline CDIPT & $\begin{array}{l}\text { CDP-diacylglycerol-inositol } \\
\text { 3-phosphatidyltransferase }\end{array}$ & 1.39 & 0.017 \\
\hline RTCA & RNA $3^{\prime}$-terminal phosphate cyclase & 1.38 & 0.0477 \\
\hline STMN1 & stathmin 1 & 1.38 & 0.0461 \\
\hline TAF11 & $\begin{array}{l}\text { TAF11 RNA polymerase II, TATA box } \\
\text { binding protein (TBP)-associated factor, } \\
28 \mathrm{kDa}\end{array}$ & 1.38 & 0.0335 \\
\hline WDR1 & WD repeat domain 1 & 1.38 & 0.0183 \\
\hline PPM1B & $\begin{array}{c}\text { protein phosphatase, } \mathrm{Mg} 2+/ \mathrm{Mn} 2+ \\
\text { dependent, } 1 \mathrm{~B}\end{array}$ & 1.37 & 0.0217 \\
\hline CAPN2 & calpain 2, (m/II) large subunit & 1.36 & 0.0454 \\
\hline LEPROTL1 & leptin receptor overlapping transcript-like 1 & 1.36 & 0.0302 \\
\hline UQCRC1 & $\begin{array}{l}\text { ubiquinol-cytochrome c reductase core } \\
\text { protein I }\end{array}$ & 1.36 & 0.0463 \\
\hline GYG1 & glycogenin 1 & 1.35 & 0.0397 \\
\hline GTF2H2 & general transcription factor IIH subunit 2 & 1.33 & 0.0127 \\
\hline$M R R F$ & mitochondrial ribosome recycling factor & 1.33 & 0.043 \\
\hline USP6NL & USP6 N-terminal like & 1.33 & 0.0103 \\
\hline SIPA1 & signal-induced proliferation-associated 1 & 1.32 & 0.0265 \\
\hline$A C L Y$ & ATP citrate lyase & 1.31 & 0.0145 \\
\hline DNAJC7 & $\begin{array}{c}\text { DnaJ (Hsp40) homolog, subfamily C, } \\
\text { member } 7\end{array}$ & 1.31 & 0.0215 \\
\hline ID1 & $\begin{array}{l}\text { inhibitor of DNA binding 1, dominant } \\
\text { negative helix-loop-helix protein }\end{array}$ & 1.31 & 0.0288 \\
\hline WDR77 & WD repeat domain 77 & 1.31 & 0.0464 \\
\hline March2 & membrane associated ring finger 2 & 1.3 & 0.043 \\
\hline CTNNB1 & catenin (cadherin-associated protein), beta 1 & 1.3 & 0.0136 \\
\hline GPR150 & G protein-coupled receptor 150 & 1.3 & 0.019 \\
\hline MYH4 & myosin, heavy chain 4 , skeletal muscle & 1.3 & 0.0378 \\
\hline$N A R F$ & nuclear prelamin A recognition factor & 1.3 & 0.0329 \\
\hline NCOA5 & nuclear receptor coactivator 5 & 1.3 & 0.0283 \\
\hline STRADA & STE20-related kinase adaptor alpha & 1.3 & 0.0316 \\
\hline ZNF576 & zinc finger protein 576 & 1.3 & 0.0243 \\
\hline
\end{tabular}

The highest expressed gene was fructosamine 3 kinase-related protein (FN3KRP), which is involved in protein deglycation by mediating phosphorylation of fructoselysine residues on glycated protein to generate fructoselysine-3 phosphate [25]. Another important upregulated gene was meteorin-like protein (METRNL), which is a hormone and is induced following exercise or cold exposure and promotes energy expenditure. It is also able to stimulate energy expenditure associated with the browning of white fat depots and thus improves glucose tolerance [26]. Ras-related protein Rab-6A $(R A B 6 A)$ is a regulator of membrane traffic from the Golgi apparatus towards the endoplasmic reticulum and has a 
low GTPase activity. From gene ontology, RAB6A was also predicted to bind to myosin $\mathrm{V}$ [27]. PSMB8 (20S proteasome subunit beta type-8) has an ATP/ubiquitin-dependent proteolytic activity and processes the class I MHC peptides as the immunoproteasome [28]. DCTN4 (dynactin subunit 4), which is a dynactin subunit p62, has been identified as an interacting partner of the P-type ATPase, ATP7B protein in mammals [29].

On the other hand, 19 downregulated genes showed fold change more than -2.0 (Table 2). Among the downregulated genes, DDX6 (DEAD box helicase 6), plays a role in the process of mRNA degradation [30]. The encoded protein of ZC3H11A (Zinc finger CCCH domain-containing protein 11A) is involved in nuclear mRNA export [31]. PRDM2 (PRdomain zinc finger protein 2 ) encoded protein is an $S$-adenosyl $-L$-methionine-dependent histone methyltransferase that explicitly methylates Lys-9 or histone $\mathrm{H} 3$ and may function as a DNA-binding transcription factor [32].

Table 2. List of downregulated genes with fold change $>1.3$ compared to control group.

\begin{tabular}{|c|c|c|c|}
\hline Gene Symbol & Description & Fold Change & $p$-Value \\
\hline DDX6 & DEAD (Asp-Glu-Ala-Asp) box helicase 6 & -3.13 & 0.0017 \\
\hline ZC3H11A & zinc finger $\mathrm{CCCH}$-type containing 11A & -2.82 & 0.0272 \\
\hline CCDC186 & coiled-coil domain containing 186 & -2.73 & 0.0399 \\
\hline PRDM2 & PR domain containing 2 , with ZNF domain & -2.61 & 0.0239 \\
\hline SPAG9 & Sperm-associated antigen 9 & -2.43 & 0.0137 \\
\hline$R B A K$ & RB-associated KRAB zinc finger & -2.41 & 0.0466 \\
\hline PRRC2C & proline-rich coiled-coil $2 \mathrm{C}^{\circ}$ & -2.4 & 0.0454 \\
\hline BOD1L1 & $\begin{array}{l}\text { biorientation of chromosomes in cell } \\
\text { division 1-like } 1\end{array}$ & -2.29 & 0.0345 \\
\hline$B A Z 1 B$ & $\begin{array}{l}\text { bromodomain adjacent to zinc finger } \\
\text { domain } 1 \mathrm{~B}\end{array}$ & -2.26 & 0.0306 \\
\hline$A L G 11$ & ALG11, alpha-1,2-mannosyltransferase & -2.25 & 0.0111 \\
\hline ZNF480 & zinc finger protein 480 & -2.22 & 0.0477 \\
\hline RNPC3 & $\begin{array}{c}\text { RNA binding region (RNP1, RRM) } \\
\text { containing } 3\end{array}$ & -2.18 & 0.0064 \\
\hline MIER1 & $\begin{array}{l}\text { mesoderm induction early response } 1, \\
\text { transcriptional regulator }\end{array}$ & -2.13 & 0.011 \\
\hline PDE4DIP & phosphodiesterase $4 \mathrm{D}$ interacting protein & -2.08 & 0.0478 \\
\hline USP1 & ubiquitin specific peptidase 1 & -2.08 & 0.0315 \\
\hline GCC2 & GRIP and coiled-coil domain containing 2 & -2.06 & 0.0378 \\
\hline TCERG1 & $\begin{array}{l}\text { transcription elongation regulator } 1 \\
\text { tyrosine 3-monooxygenase/tryptophan }\end{array}$ & -2.06 & 0.0152 \\
\hline YWHAE & $\begin{array}{l}\text { 5-monooxygenase activation protein, } \\
\text { epsilon }\end{array}$ & -2.05 & 0.0491 \\
\hline LMAN1 & lectin, mannose-binding, 1 & -2.02 & 0.0137 \\
\hline CEP57 & centrosomal protein $57 \mathrm{kDa}$ & -2.01 & 0.0241 \\
\hline NBPF10 & neuroblastoma breakpoint family, member & -1.99 & 0.0261 \\
\hline WASL & Wiskott-Aldrich syndrome-like & -1.99 & 0.0414 \\
\hline WHSC1L1 & $\begin{array}{l}\text { Wolf-Hirschhorn syndrome candidate } \\
\text { 1-like } 1\end{array}$ & -1.99 & 0.0163 \\
\hline SWAP70 & $\begin{array}{l}\text { SWAP switching B-cell complex } 70 \mathrm{kDa} \\
\text { subunit }\end{array}$ & -1.95 & 0.0452 \\
\hline EFCAB14 & EF-hand calcium binding domain 14 & -1.9 & 0.0187 \\
\hline EIF4G1 & $\begin{array}{l}\text { eukaryotic translation initiation factor } 4 \\
\text { gamma, } 1\end{array}$ & -1.88 & 0.0381 \\
\hline KMT2C & lysine $(\mathrm{K})$-specific methyltransferase $2 \mathrm{C}$ & -1.87 & 0.0496 \\
\hline TNKS2 & $\begin{array}{c}\text { tankyrase, TRF1-interacting ankyrin-related } \\
\text { ADP-ribose polymerase } 2\end{array}$ & -1.86 & 0.0056 \\
\hline IL6ST & interleukin 6 signal transducer & -1.84 & 0.0118 \\
\hline SON & SON DNA binding protein & -1.8 & 0.0463 \\
\hline FAM107B & $\begin{array}{l}\text { family with sequence similarity } 107, \\
\text { member B }\end{array}$ & -1.78 & 0.0437 \\
\hline SF3B1 & splicing factor $3 \mathrm{~b}$, subunit $1,155 \mathrm{kDa}$ & -1.76 & 0.0248 \\
\hline
\end{tabular}


Table 2. Cont.

\begin{tabular}{|c|c|c|c|}
\hline Gene Symbol & Description & Fold Change & $p$-Value \\
\hline OTUD4 & OTU deubiquitinase 4 & -1.75 & 0.0445 \\
\hline PPIG & peptidylprolyl isomerase G (cyclophilin G) & -1.75 & 0.0348 \\
\hline PEG10 & paternally expressed 10 & -1.71 & 0.0298 \\
\hline CBX5 & chromobox homolog 5 & -1.69 & 0.0143 \\
\hline KMT2A & lysine (K)-specific methyltransferase 2A & -1.68 & 0.0378 \\
\hline ANKRD12 & ankyrin repeat domain 12 & -1.63 & 0.0372 \\
\hline AP3M2 & $\begin{array}{l}\text { adaptor-related protein complex } 3, \text { mu } 2 \\
\text { subunit }\end{array}$ & -1.62 & 0.0284 \\
\hline REST & RE1-silencing transcription factor & -1.62 & 0.0308 \\
\hline WAC & $\begin{array}{l}\text { WW domain containing adaptor with } \\
\text { coiled-coil }\end{array}$ & -1.62 & 0.0225 \\
\hline CTDSPL2 & CTD small phosphatase like 2 & -1.61 & 0.0333 \\
\hline DNAJB14 & $\begin{array}{c}\text { DnaJ (Hsp40) homolog, subfamily B, } \\
\text { member } 14\end{array}$ & -1.6 & 0.0244 \\
\hline ZNF208 & zinc finger protein 208 & -1.59 & 0.0076 \\
\hline CRCP & CGRP receptor component & -1.58 & 0.0169 \\
\hline MLLT4 & $\begin{array}{l}\text { myeloid/lymphoid or mixed-lineage } \\
\text { leukemia; translocated to, } 4\end{array}$ & -1.58 & 0.0077 \\
\hline PCM1 & pericentriolar material 1 & -1.57 & 0.0419 \\
\hline MBNL2 & muscleblind-like splicing regulator 2 & -1.55 & 0.0136 \\
\hline AKAP9 & A kinase (PRKA) anchor protein 9 & -1.53 & 0.0383 \\
\hline HSP90B1 & $\begin{array}{l}\text { heat shock protein 90kDa beta (Grp94), } \\
\text { member } 1\end{array}$ & -1.53 & 0.044 \\
\hline MCFD2 & multiple coagulation factor deficiency 2 & -1.53 & 0.0194 \\
\hline$S M C 1 A$ & structural maintenance of chromosomes $1 \mathrm{~A}$ & -1.52 & 0.0205 \\
\hline SMC5 & structural maintenance of chromosomes 5 & -1.52 & 0.0407 \\
\hline GOLGA2 & golgin $\mathrm{A} 2$ & -1.51 & 0.0456 \\
\hline LRP10 & LDL receptor-related protein 10 & -1.51 & 0.0223 \\
\hline РТР4A2 & $\begin{array}{c}\text { protein tyrosine phosphatase type IVA, } \\
\text { member } 2\end{array}$ & -1.51 & 0.0303 \\
\hline$S K I$ & SKI proto-oncogene & -1.5 & 0.0161 \\
\hline SPIN1 & spindlin 1 & -1.5 & 0.0389 \\
\hline$L G A L S L$ & lectin, galactoside-binding-like & -1.49 & 0.0259 \\
\hline MYH11 & myosin, heavy chain 11 , smooth muscle & -1.49 & 0.0071 \\
\hline TBC1D23 & TBC1 domain family, member 23 & -1.49 & 0.0272 \\
\hline DYM & dymeclin & -1.48 & 0.027 \\
\hline GAPVD1 & $\begin{array}{l}\text { GTPase-activating protein and VPS9 } \\
\text { domains } 1\end{array}$ & -1.48 & 0.0319 \\
\hline PGAM5 & $\begin{array}{l}\text { PGAM family member } 5 \text {, serine/threonine } \\
\text { protein phosphatase, mitochondrial }\end{array}$ & -1.47 & 0.0211 \\
\hline SUPT2OH & SPT20 homolog, SAGA complex component & -1.47 & 0.039 \\
\hline$M G A$ & MGA, MAX dimerization protein & -1.46 & 0.0043 \\
\hline SGMS2 & sphingomyelin synthase 2 & -1.46 & 0.0256 \\
\hline ZNF91 & zinc finger protein 91 & -1.46 & 0.0258 \\
\hline PAPOLA & poly(A) polymerase alpha & -1.45 & 0.0277 \\
\hline PHF24 & PHD finger protein 24 & -1.45 & 0.039 \\
\hline CNOT4 & CCR4-NOT transcription complex subunit 4 & -1.44 & 0.0162 \\
\hline KTN1 & kinectin 1 (kinesin receptor) & -1.43 & 0.0406 \\
\hline MAP4K5 & mitogen-activated protein kinase 5 & -1.43 & 0.0129 \\
\hline ZNF766 & zinc finger protein 766 & -1.43 & 0.0093 \\
\hline CDK12 & cyclin-dependent kinase 12 & -1.42 & 0.0343 \\
\hline ITGAD & integrin alpha D & -1.41 & 0.0217 \\
\hline MGEA5 & $\begin{array}{c}\text { meningioma expressed antigen } 5 \\
\text { (hyaluronidase) }\end{array}$ & -1.41 & 0.0036 \\
\hline ATF6 & activating transcription factor 6 & -1.4 & 0.0175 \\
\hline DNASE1 & deoxyribonuclease I & -1.4 & 0.024 \\
\hline PRPF $40 A$ & $\begin{array}{c}\text { PRP40 pre-mRNA processing factor } 40 \\
\text { homolog A }\end{array}$ & -1.39 & 0.0491 \\
\hline RAB11FIP1 & RAB11 family interacting protein 1 (class I) & -1.39 & 0.0298 \\
\hline
\end{tabular}


Table 2. Cont.

\begin{tabular}{|c|c|c|c|}
\hline Gene Symbol & Description & Fold Change & $p$-Value \\
\hline$D D R 2$ & discoidin domain receptor tyrosine kinase 2 & -1.38 & 0.0287 \\
\hline EPRS & glutamyl-prolyl-tRNA synthetase & -1.38 & 0.0102 \\
\hline HN1L & $\begin{array}{l}\text { hematological and neurological expressed } \\
\text { 1-like }\end{array}$ & -1.38 & 0.0201 \\
\hline MEI1 & $\begin{array}{l}\text { meiotic double-stranded break formation } \\
\text { protein } 1\end{array}$ & -1.38 & 0.043 \\
\hline PAPD5 & PAP-associated domain containing 5 & -1.38 & 0.0489 \\
\hline PIK3C2A & $\begin{array}{l}\text { phosphatidylinositol-4-phosphate 3-kinase, } \\
\text { catalytic subunit type } 2 \text { alpha }\end{array}$ & -1.38 & 0.0064 \\
\hline UBE2J1 & ubiquitin-conjugating enzyme E2, J1 & -1.38 & 0.0219 \\
\hline UBXN4 & UBX domain protein 4 & -1.38 & 0.0492 \\
\hline CCDC50 & coiled-coil domain containing 50 & -1.37 & 0.0247 \\
\hline GCK & glucokinase (hexokinase 4) & -1.37 & 0.0178 \\
\hline PLA2G5 & phospholipase A2, group V & -1.37 & 0.01 \\
\hline PTPRE & protein tyrosine phosphatase, receptor type, & -1.37 & 0.0491 \\
\hline ARHGAP35 & Rho GTPase activating protein 35 & -1.36 & 0.0299 \\
\hline PRKAR2A & $\begin{array}{l}\text { protein kinase, cAMP-dependent, } \\
\text { regulatory, type II, alpha }\end{array}$ & -1.35 & 0.0455 \\
\hline TLK1 & tousled-like kinase 1 & -1.35 & 0.0076 \\
\hline AFF1 & AF4/FMR2 family, member 1 & -1.34 & 0.0214 \\
\hline LINC00303 & long intergenic non-protein coding RNA 303 & -1.34 & 0.0341 \\
\hline OR5AK2 & $\begin{array}{c}\text { olfactory receptor, family } 5 \text {, subfamily } \mathrm{AK}, \\
\text { member } 2\end{array}$ & -1.34 & 0.0287 \\
\hline PCLO & piccolo presynaptic cytomatrix protein & -1.34 & 0.0089 \\
\hline CCDC30 & coiled-coil domain containing 30 & -1.33 & 0.0115 \\
\hline$C D C 40$ & cell division cycle 40 & -1.33 & 0.0303 \\
\hline DNAJB5 & $\begin{array}{l}\text { DnaJ (Hsp40) homolog, subfamily B, } \\
\text { member } 5\end{array}$ & -1.33 & 0.0228 \\
\hline RMI1 & RecQ mediated genome instability 1 & -1.33 & 0.0495 \\
\hline SLC25A36 & $\begin{array}{l}\text { solute carrier family } 25 \text { (pyrimidine } \\
\text { nucleotide carrier), member } 36\end{array}$ & -1.33 & 0.0231 \\
\hline ZNF215 & zinc finger protein 215 & -1.33 & 0.0353 \\
\hline MAGEC3 & MAGE family member C3 & -1.32 & 0.0298 \\
\hline SLC35E4 & solute carrier family 35 , member E4 & -1.32 & 0.0151 \\
\hline$A T P 2 A 2$ & $\begin{array}{c}\text { ATPase, } \mathrm{Ca}++ \text { transporting, cardiac muscle, } \\
\text { slow twitch } 2\end{array}$ & -1.31 & 0.0405 \\
\hline FAM120A & family with sequence similarity 120A & -1.31 & 0.0195 \\
\hline FAM208B & $\begin{array}{l}\text { family with sequence similarity } 208, \\
\text { member B }\end{array}$ & -1.31 & 0.0302 \\
\hline KATNBL1 & katanin p80 subunit B-like 1 & -1.31 & 0.049 \\
\hline MFSD12 & $\begin{array}{l}\text { major facilitator superfamily domain } \\
\text { containing } 12\end{array}$ & -1.31 & 0.0399 \\
\hline MT1A & metallothionein $1 \mathrm{~A}$ & -1.31 & 0.0471 \\
\hline ZNF609 & zinc finger protein 609 & -1.31 & 0.0383 \\
\hline ZNF750 & zinc finger protein 750 & -1.31 & 0.0259 \\
\hline$H L A-D O A$ & $\begin{array}{l}\text { major histocompatibility complex, class II, } \\
\text { DO alpha }\end{array}$ & -1.3 & 0.0497 \\
\hline KCNE4 & $\begin{array}{l}\text { potassium channel, voltage gated subfamily } \\
\text { E regulatory beta subunit } 4\end{array}$ & -1.3 & 0.0429 \\
\hline LINC00656 & long intergenic non-protein coding RNA 656 & -1.3 & 0.0252 \\
\hline LINC01118 & $\begin{array}{c}\text { long intergenic non-protein coding RNA } \\
1118\end{array}$ & -1.3 & 0.0228 \\
\hline OR1M1 & $\begin{array}{l}\text { olfactory receptor, family } 1 \text {, subfamily } \mathrm{M} \text {, } \\
\text { member } 1\end{array}$ & -1.3 & 0.0127 \\
\hline OSBPL8 & oxysterol binding protein-like 8 & -1.3 & 0.0323 \\
\hline RPAP2 & RNA polymerase II-associated protein 2 & -1.3 & 0.0153 \\
\hline ZNF257 & zinc finger protein 257 & -1.3 & 0.0266 \\
\hline
\end{tabular}




\subsection{Significantly Enriched Gene Sets and Gene Ontologies (GO)}

For the GO analysis, we considered the genes with fold change $>1.3$ and $p$-value $<0.05$ as the differentially expressed genes (DEGs) (Table 1). Upregulated DEGs ( $>1.3$-fold change) were $37(23 \%)$ and downregulated DEGs (1.3-fold $>$ ) were 124 (57\%) (Figure 1B).

We analyzed the DEGs by enrichment analysis using the Database for Annotation, Visualization, and Integrated Discovery (DAVID) online tool. The upregulated DEGs were categorized into nine clusters based on $\mathrm{GO}$ terms of biological process (BP), eight clusters based on cellular components (CC), and three clusters based on molecular functions (MF). In the BP, five gene sets were significantly enriched $(p<0.05)$, containing the GO terms "positive regulation of fibroblast growth factor receptor signaling pathway (GO:0045743)", "response to muscle activity (GO:0014850)", "male genitalia development (GO:0030539)", "regulation of cytoskeleton organization (GO:0051493)", and "transcription initiation from RNA polymerase II promoter (GO:0006367)" (Figure 2A). In the CC, three gene sets were significantly enriched $(p<0.05)$, containing GO terms "cytosol (GO:0005829)", "myelin sheath (GO:0043209)", and "nucleoplasm (GO:0005654)" (Figure 2B). In the MF, one gene set, containing a term "protein N-terminus binding (GO:0047485)" was significantly enriched $(p<0.05)$ (Figure 2C).

A

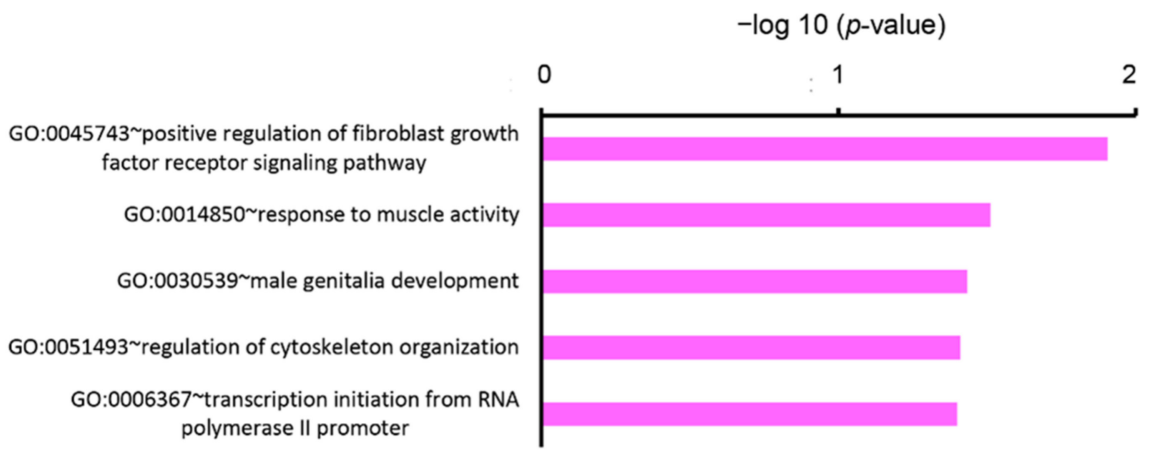

B

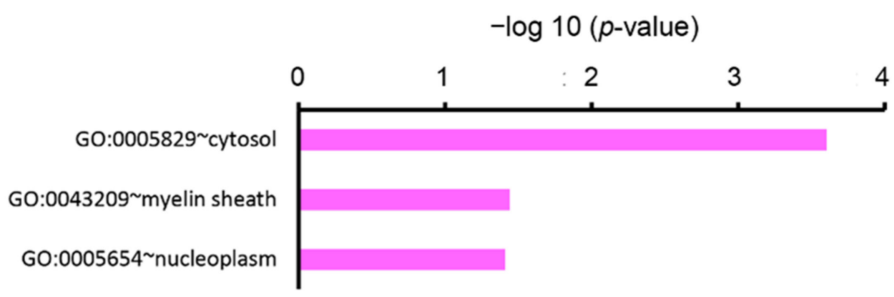

C

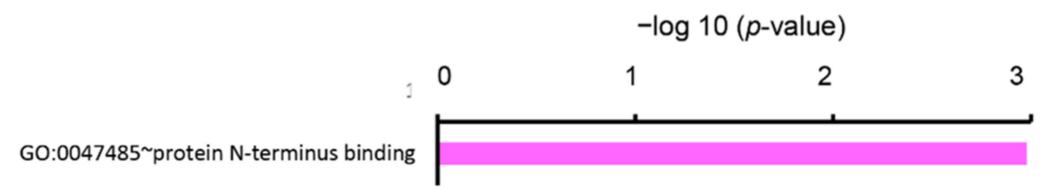

Figure 2. Functional analysis of upregulated DEGs between Cy3G-treated and untreated hAECs on day 7 represented (A) significantly enriched biological process, (B) cellular components, and (C) molecular functions analyzed by the Database for Annotation, Visualization, and Integrated Discovery (DAVID). The horizontal axis corresponds to $-\log 10 p$-value.

On the other hand, the downregulated DEGs were categorized into 22 clusters based on BP, 14 clusters based on CC, and 13 clusters based on MF. In the BP, 11 gene sets were significantly enriched $(p<0.05)$, containing GO terms "cell-cell adhesion (GO:0098609)", "microtubule anchoring (GO:0034453)", "RNA splicing (GO:0008380)", "negative regulation of peptidyl-serine dephosphorylation (GO:1902309)", "protein $N$-linked glycosylation via asparagine (GO:0018279)", "transcription, DNA templated (GO:0006351)", "cellular response to DNA damage stimulus (GO:0006974)", "regulation of cardiac muscle cell 
action potential involved in the regulation of contraction (GO:0098909)" (Figure 3A). In the CC, nine gene sets were significantly enriched $(p<0.05)$, containing GO terms "nucleoplasm (GO:0005654)", "nucleus (0005634)", "cell-cell adherens junction (GO:0005913)", "transcriptional repressor complex (GO:0017053)", "membrane (GO:0016020)", "nuclear speck (GO:0016607)", “histone methyltransferase complex (GO:0035097)", "nuclear envelope (GO:0005635)", and "Golgi apparatus (GO:0005794)" (Figure 3B). In the MF, six gene sets were significantly enriched $(p<0.05)$, containing GO terms "poly (A) RNA binding (GO:0044822)", "histone-lysine $N$-methyltransferase activity (GO:0005789)", "cadherin binding involved in cell-cell adhesion (GO:0098641)", "protein binding (GO:0005515)", "core promoter sequence-specific DNA binding (GO:0001046)", "ubiquitin-protein ligase binding (GO:0031625)", "chromatin binding (GO:0003682)", "ATP binding (GO:0005524)", and "polynucleotide adenyl transferase activity (GO:0004652)" (Figure 3C).

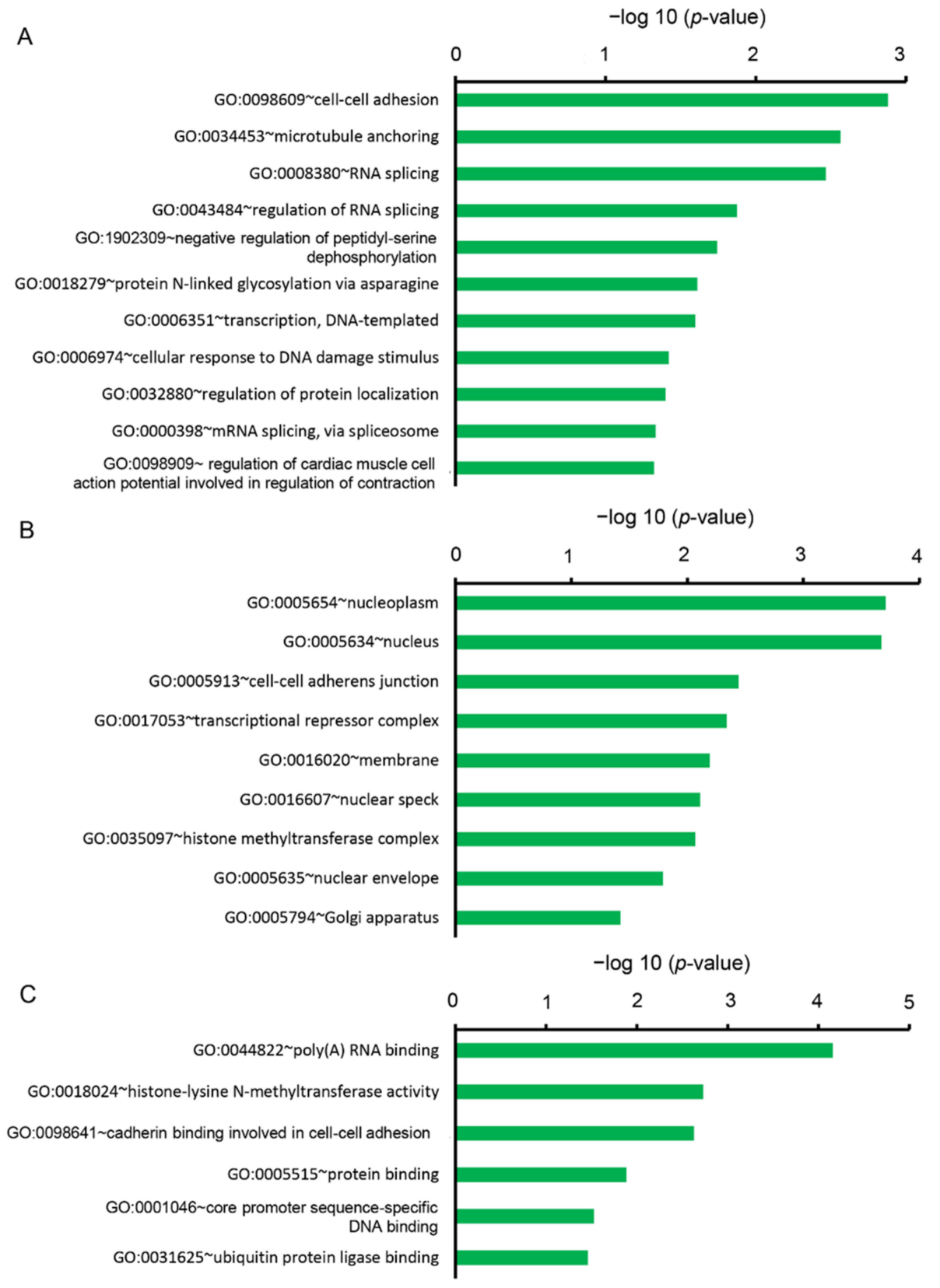

Figure 3. Functional analysis of downregulated DEGs between Cy3G-treated and untreated hAECs on day 7 by DAVID represented (A) significantly enriched biological process, (B) cellular components, and (C) molecular functions. The horizontal axis corresponds to $-\log 10 p$-value. 
Furthermore, we analyzed the DEGs using the Molecular Signatures Database (MSigDB) online tool. The upregulated DEGs were categorized into 10 gene sets and the downregulated DEGs were categorized into 20 gene sets. The top enriched GO terms by upregulated DEGs included "protein N-terminus binding", "positive regulation of cellular component organization", "RNA polymerase II transcription factor complex", and "positive regulation of fibroblast growth factor receptor signaling pathway" (Figure 4A). Top enriched GO by the downregulated DEGs were "RNA binding", "organelle localization", "adenyl nucleotide binding", "cell cycle", and "mRNA metabolic process" (Figure 4B).

A $-\log 10$ (p-value)

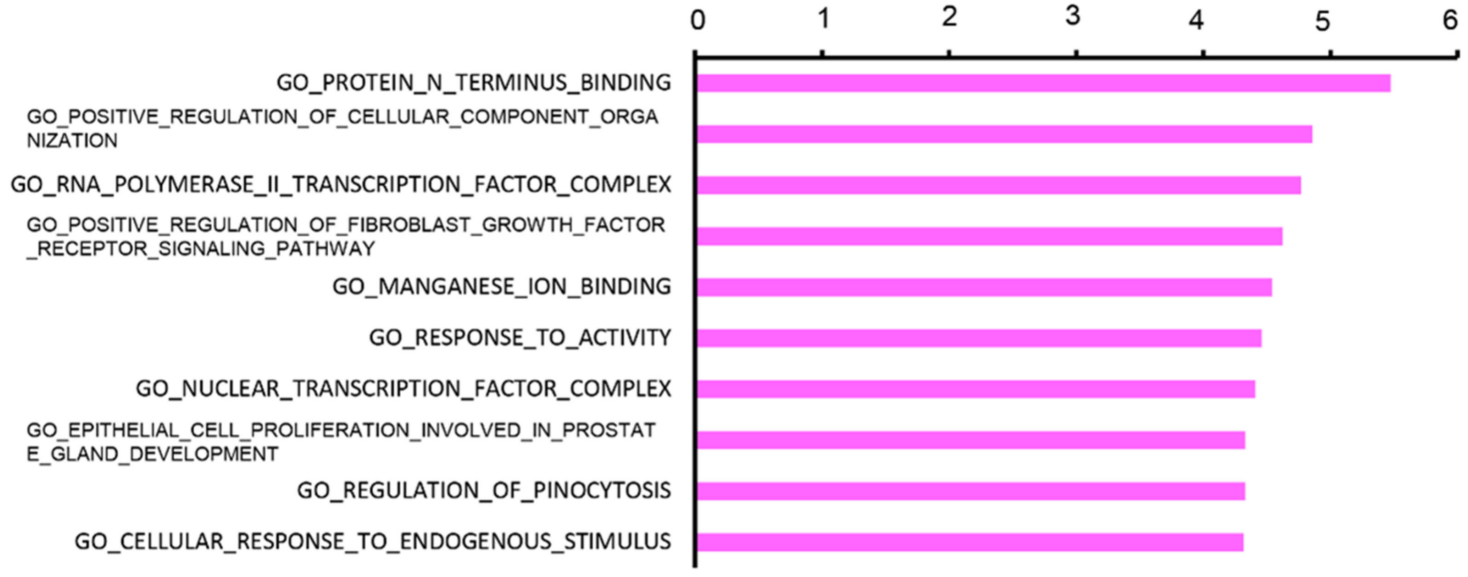

B

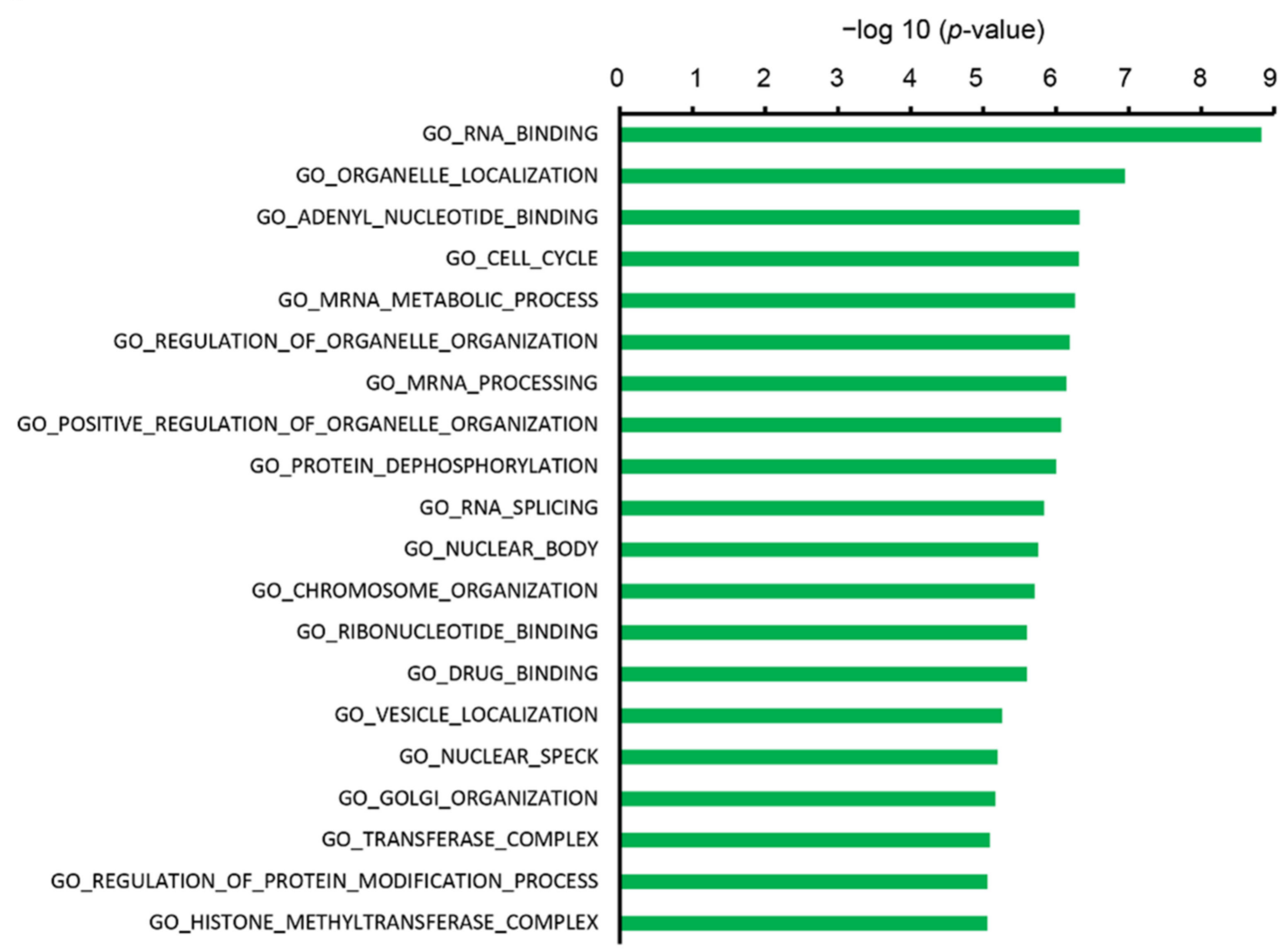

Figure 4. Functional analysis of DEGs between Cy3G-treated and untreated hAECs on day 7 in (A) upregulated and (B) downregulated genes analyzed by the Molecular Signatures Database (MSigDB). The horizontal axis corresponds to $-\log 10$ $p$-value. 


\section{Discussion}

Cyanidin has several bioactivities in mammals. Previous reports indicate that cyanidin may affect the differentiation of PSCs and adult stem cells. Cy3G has been reported to regulate the differentiation of RANKL-induced osteoclasts, which are multi-nucleated cells derived from hematopoietic stem cells (HSCs), and enhance cell fusion [33]. LnCap and DU145 human prostate cancer cells treated with Cyanidin-3-O- $\beta$-glucopyranoside showed anti-proliferative and pro-differentiation properties [17]. However, the effects of cyanidin on hAECs have not been investigated.

Enrichment analysis of Cy3G-treated hAECs showed that response to muscle activityrelated genes, namely METRNL and SRD5A1, were upregulated (Table 3).

Table 3. Top enriched gene ontology clusters by the upregulated genes analysis by the DAVID.

\begin{tabular}{cc}
\hline Biological Process & Genes \\
\hline Term & CTNNB1, NPTN \\
\hline $\begin{array}{c}\text { GO:0045743 positive regulation of fibroblast } \\
\text { growth factor receptor signaling pathway }\end{array}$ & METRNL, SRD5A1 \\
\hline GO:0014850 response to muscle activity & CTNNB1, SRD5A1 \\
\hline GO:0030539 male genitalia development & CAPN2, STMN1 \\
\hline $\begin{array}{c}\text { GO:0051493 regulation of cytoskeleton } \\
\text { organization }\end{array}$ & TAF11, GTF2H2, NR1H2 \\
\hline $\begin{array}{c}\text { GO:0006367 transcription initiation from RNA } \\
\text { polymerase II promoter }\end{array}$ & Genes \\
\hline Cellular Component & ACLY, DNAJC7, RAPGEF6, STRADA, USP6NL, \\
\hline Term & WRD3KRP, GYG1, PAPN2, CTNNB, PPM1B, SIPA1, \\
& STMN1 \\
\hline GO:0005829 cytosol & WRD1, SRD5A1, UQCRC1 \\
\hline GO:0043209 myelin sheath & ACLY, DNAJC7, RTCA, STRADA, TAF11, \\
\hline GO:0005654 nucleoplasm & WRD77, CTNNB1, GTF2H2, ID1, NR1H2, \\
& PSMB8 \\
\hline Molecular Function & Genes \\
\hline Term & TAF11, DCTN4, GTF2H2, ID1 \\
\hline GO:0047485 protein N-terminus binding &
\end{tabular}

Metrnl is reported to have multifaceted functions in adipocyte differentiation concerned to brown fat cell differentiation of adipocyte [34]. Brown adipose tissue can dissipate energy compared to white adipose tissue. White adipose tissue possesses the capacity to generate brown-like adipocytes, termed beiging [35]. Metrnl was identified as a peroxisome proliferator-activated receptor gamma coactivator (PGC)-1 $\alpha 4$-dependent myokine and can be induced in muscle after exercise. Increased circulating levels of Metrnl indicates stimulated energy expenditure and improved glucose tolerance [34]. These changes are activated by the adaptive responses of cells to the environmental or intracellular stress stimuli, thus counteracting the stress and promoting cell survival [36]. Overexpressed Metrnl also upregulated the peroxisome proliferator-activated receptor gamma (PPAR $\gamma$ ) and anti-inflammatory cytokines in white adipocytes [34].

Interestingly, in the skeletal muscle of Cy3G-administered mice, PGC- $1 \alpha$ was upregulated via cyclic AMP (cAMP) elevation, which subsequently enhanced exercise performance [19]. Cy3G also induces the differentiation of the beige phenotypes via elevations 
of cAMP level, PGC-1 $\alpha$, and PPAR $\gamma$ in mice adipocyte cells [19]. These previous reports support our findings in transcriptome data using Cy3G-treated hAECs.

Another gene, SRD5A1, converts testosterone into 5-alpha-dihydrotestosterone and progesterone or corticosterone into their corresponding 5-alpha-3-oxosteroids, and has a central role in sexual differentiation and androgen physiology. Male mouse that lacked 5alpha-reductase type 1 (SRD5A1) has reduced bone and forelimb muscle grip strength [37]. Expression of SRD5A1 was found in human adipose tissues, where it shows a tendency to increase slightly with differentiation in preadipocytes [38].

PSMB8, a catalytic subunit for immunoproteasomes, also regulates the differentiation of preadipocytes and the differentiation of preadipocytes to mature adipocytes in mice. Psmb8-/ - mice show reduced weight gain caused by a reduction in adipose tissue volume and small size of mature adipocytes. In addition, inhibition of Psmb8 in 3T3L1 mice adipocyte cells could disrupt the differentiation to mature cells [39].

In our study, enrichment analysis also showed upregulation of genes related to regulation of cytoskeleton organization such as CAPN2 and STMN1 (Table 3). CAPN2 encodes calpain-2 catalytic subunit, which is a calcium-regulated non-lysosomal thiol-protease. It catalyzes limited proteolysis of substrates involved in cytoskeletal remodeling and signal transduction [40]. STMN1 encodes Stathmin, which is involved in the regulation of the microtubule filament system by destabilizing microtubules. Cytoskeleton remodeling is one of the first steps for the morphological transition from preadipocyte to mature adipocyte. Acetylation of $\alpha$-tubulin is related to adipogenesis in mice and 3T3-L1 cells [41].

A downregulated gene, DDX6, which encodes DEAD-box helicase 6 protein, has been reported to function in adipogenesis. In human adipose tissue-derived stem cells, the number of DDX6 granules per cell was reduced during adipogenesis [42].

Enrichment analysis showed cell cycle-related genes were downregulated in the Cy3G-treated hAECs. This gene set includes 21 genes as follows: YMHAE, EIF4G1, SMC1A, TENT4B, PRPF40A, SON, CNOT4, WASL, AKAP9, MEI1, GOGGA2, CEP57, PCM1, CDK12, SMC5, TLK1, WAC, CBX5, RMI1, SPIN1, and MGA. CDK12, which encodes cycle dependent kinase 12 , is associated with elongating RNA polymerase II and its activity is required for G1/S progression [43]. SMC1A encodes a protein of central component of chromosome cohesion complex during cell cycles [44]. Cell cycle is an important event during cell proliferation but not necessary during cell differentiation. The length of G1 phase arrest is important for the decision of proliferation or differentiation [45]. In Cy3G- treated AECs, downregulation of genes related to G1/S progression may be indicated of the induction of differentiation in hAECs.

Previously, Kim et al. (2012) reported that anthocyanin extracts from black soybeans comprising Cy3G (68.3\%) as well as delphinidin-3-O-glucoside (25.2\%) and petunidin-3O-glucoside $(6.5 \%)$ could inhibit adipocyte differentiation and basal lipolysis in 3T3-L1 cell line [46]. Another study by Jeon et al. (2015) reported that the ethanol testa-extract of black soybean might suppress the differentiation of subcutaneous adipose-derived stem cells into the precursor cells of adipocytes [47]. However, adipocyte phenotype was studied in neither of the studies. We have reported in our previous studies that Cy3G, both synthetic and derived from black soybeans, could induce beige phenotype of adipocyte differentiation in mouse preadipocyte 3T3-L1 cells and improves insulin resistance [3,20].

Natural bioactive compounds have great potential to induce the targeted differentiation of stem cells in a lineage-specific manner by modulating cellular behavior and early biological and molecular events; however, only a handful of studies explored it. In our previous studies, we have reported that a caffeic acid ester (rosmarinic acid), a caffeoylquinic acid derivative (TCQA), and an iridoid glycoside (verbenalin) directed the differentiation of hAECs towards neuronal-lineage, whereas a flavonol aglycone isorhamnetin induced hepatic-lineage specific differentiation in hAECs [8-11]. We assume that other compounds from the anthocyanin group may have a similar effect as Cy3G on hAEC's fate choice. Their efficacy may vary depending on the presence or absence as well as the position of the sugar moieties. Therefore, the role of different anthocyanins on modulating adipocyte 
differentiation in hAECs should be explored further. Additionally, assessments of the effects of $\mathrm{Cy} 3 \mathrm{G}$ on protein levels is required to confirm our observational transcriptomic analysis findings.

Altogether, our findings suggest that Cy3G may have prospects in inducing adipocyte differentiation in hAECs. Although hAECs have multilineage differentiation potential [7,48], their adipogenic differentiation is still controversial. While some reported adipogenic differentiation of hAECs under proper culture conditions [49-51], others did not find any adipogenic differentiation potential of hAECs [52,53]. Therefore, adipocyte differentiationenhancing effects of $\mathrm{Cy} 3 \mathrm{G}$, a plant-based compound, in hAECs in the absence of any growth factors and cytokines, may have an important step towards clinical applications of hAECs in reconstructive, corrective, and cosmetic fields. However, further in-depth investigation to validate our primary findings is warranted.

\section{Materials and Methods}

\subsection{Extraction of AECs and Cell Culture Maintenance}

Isolation of amnion epithelial cells (AECs) and their culturing was followed by the methods described previously [8,9]. In brief, the amnion was aseptically separated from the chorion and washed with Hank's Basic Salt Solution -Calcium and Magnesium Free (CMF-HBSS, Wako Pure Chemical Industries Ltd., Osaka, Japan). The smaller pieces of amnion were treated with a pre-digestion buffer (CMF-HBSS with EGTA, Wako Pure Chemical Industries Ltd., Osaka, Japan), rocked in the solution, and incubated for $10 \mathrm{~min}$ at $37^{\circ} \mathrm{C}$. After incubation, the Trypsin-EDTA was added to the tissue and incubated for $40 \mathrm{~min}$ at $37^{\circ} \mathrm{C}$ and then transferred on ice. Dulbecco's Modified Eagle Medium (DMEM, Sigma-Aldrich, St.-Louis, MI, USA) with FBS (Thermo Fisher Scientific Inc., Waltham, MA, USA) and penicillin-streptomycin (Lonza Walkersville Inc., Walkersville, MD, USA) was added to the trypsin digest. After centrifugation, pellets were resuspended and filtered through a $100 \mathrm{~mm}$ filter. The cell suspension was collected.

To maintain the AECs, the cells were cultured in Placenta Epithelial Cell Basal Medium (PromoCell, Cat. \#C-26140, Heidelberg, Germany) and monitored continuously with media change every $2-4$ days.

\subsection{Three-Dimension Amnion Epithelial Cells, Culture Spheroid Formation, and Treatment with Cyanidin}

To culture the hAECs, we employed the 3D culture Plate system (Elplasia ${ }^{\mathrm{TM}}$, Kuraray Co. Ltd., Kurashiki, Japan). Spheroids were formed by seeding $1 \times 10^{6}$ AECs in Placenta Basal Epithelial Cell Medium into each well of the 24-well plate. The initial culture was maintained for $24 \mathrm{~h}$. After the initial $24 \mathrm{~h}$ culture, the medium was changed with $20 \mu \mathrm{M}$ of Cy3G (Tokiwa Phytochemical Co. Ltd., Chiba, Japan; purity on HPLC $\geq 98 \%$ ) every $48 \mathrm{~h}$ three times for the treatment samples (Day 2, 4, and 6). Control samples were maintained in the Placenta Epithelial Cell Basal Medium that was also changed every $48 \mathrm{~h}$ (Day 2, 4, and 6). Finally, we collected RNA samples from the Cy3G-treated and control AECs on day 7.

\subsection{RNA Extraction and Microarray Analysis}

Total RNA was isolated using ISOGEN (Nippon Gene, Tokyo, Japan), according to the manufacturer's instructions. The amplified RNA (aRNA) was synthesized using the Gene Chip 3' IVT PLUS Reagent Kit (Thermo Fisher Scientific Inc., Waltham, MA, USA). Hybridization was achieved using the Affymetrix GeneChip Human Genome U219 Array Strip (HG-U219, Thermo Fisher Scientific). The images were obtained by the GeneAtlas ${ }^{\text {TM }}$ Imaging Station and analyzed using the GeneAtlas ${ }^{\mathrm{TM}}$ Workstation (Thermo Fisher Scientific), according to the manufacturer's instructions. Microarray expression profiling was conducted for two biological replicates of Cy3G-treated samples (Cy7) and untreated control samples (D7). 


\subsection{Microarray Analysis for Gene Expression Profiling in Cy3G-Treated hAECs}

The data of DNA microarrays (Cy7 and D7) were classified and analyzed by the gene set enrichment analysis approach, using the DAVID server, v6.8 (National Institute of Allergy and Infectious Diseases (NIAID), NIH, USA, https:/ / david.ncifcrf.gov/, accessed on 16 April 2020) [54,55]. The data sets were also analyzed by the MSigDB v7.1 (Gene Set E nrichment Analysis, UC San Diego, https:/ / www.gsea-msigdb.org/gsea/msigdb/index. jsp, accessed on 16 April 2020).

\subsection{Ethics Approval}

In the present study, we have used hAECs that were preserved at the Tsukuba Human Tissue Biobank Center (THB). THB was established at the University of Tsukuba in November 2013 with an aim to reserve human biospecimens to promote medical research [56,57]. The protocol for isolation, collection, and use of hAECs and other biospecimens was approved by the Ethical Review Committee of the University of Tsukuba Hospital (approval code: H27-58, approval date: 10 July, 2015). Informed written consent was obtained from the mothers who donated the placenta.

Author Contributions: S.T.: investigation, methodology, formal analysis, data curation, software, visualization, writing-original draft; F.F.: investigation, methodology, data curation, writingreview \& editing; Y.-W.Z.: investigation, validation, resources; T.O. and H.I.: conceptualization, methodology, resources, supervision, project administration, funding acquisition, writing-review \& editing. All authors have read and agreed to the published version of the manuscript.

Funding: This research was partially supported by Japan Science and Technology Agency (JST); Science and Technology Research Partnership for Sustainable Development (SATREPS, Grant No. JPMJSA1506).

Institutional Review Board Statement: The protocol for isolation, collection, and use of hAECs and other biospecimens for research purposes was carried out in accordance with the Japan's Ministry of Education, Culture, Sports, Science and Technology's "Bioethics and Safety Initiatives" and was compliant with the guidelines of the Declaration of Helsinki. The protocol was approved by the Ethical Review Committee of the University of Tsukuba Hospital (approval code: H27-58, approval date: 10 July 2015).

Informed Consent Statement: Informed written consent was obtained from the mothers who donated the placenta.

Data Availability Statement: All data generated or analyzed during this study are included in this published article and its supplementary information files. Microarray data are deposited in the Gene Expression Omnibus (GEO) under Accession Number: GSE148776 (https:/ / www.ncbi.nlm.nih.gov / geo/query/acc.cgi?acc=GSE148776, accessed on 16 April 2020).

Acknowledgments: We thankfully acknowledge Kinji Furuya and Kazunori Sasaki for their support for hAECs and RNA isolation, respectively. We also acknowledge Shinji Kondo for his suggestions about adipogenesis and cell differentiation.

Conflicts of Interest: The authors declare that the research was conducted in the absence of any commercial or financial relationships that could be construed as a potential conflict of interest.

\section{References}

1. Cartea, M.E.; Francisco, M.; Soengas, P.; Velasco, P. Phenolic Compounds in Brassica Vegetables. Molecules 2011, 16, 251-280. [CrossRef] [PubMed]

2. Arts, I.C.; Hollman, P.C. Polyphenols and disease risk in epidemiologic studies. Am. J. Clin. Nutr. 2005, 81 (Suppl. S1), 317S-325S [CrossRef]

3. Matsukawa, T.; Inaguma, T.; Han, J.; Villareal, M.O.; Isoda, H. Cyanidin-3-glucoside derived from black soybeans ameliorate type 2 diabetes through the induction of differentiation of preadipocytes into smaller and insulin-sensitive adipocytes. J. Nutr. Biochem. 2015, 26, 860-867. [CrossRef] [PubMed]

4. Manach, C.; Scalbert, A.; Morand, C.; Rémésy, C.; Jiménez, L. Polyphenols: Food sources and bioavailability. Am. J. Clin. Nutr. 2004, 79, 727-747. [CrossRef] 
5. Liu, R.H. Health benefits of fruit and vegetables are from additive and synergistic combinations of phytochemicals. Am. J. Clin. Nutr. 2003, 78, 517s-520s. [CrossRef]

6. Fraga, C.G.; Galleano, M.; Verstraeten, S.V.; Oteiza, P.I. Basic biochemical mechanisms behind the health benefits of polyphenols. Mol. Asp. Med. 2010, 31, 435-445. [CrossRef] [PubMed]

7. Miki, T. Amnion-derived stem cells: In quest of clinical applications. Stem Cell Res. Ther. 2011, 2, 1-11. [CrossRef] [PubMed]

8. Ferdousi, F.; Kondo, S.; Sasaki, K.; Uchida, Y.; Ohkohchi, N.; Zheng, Y.W.; Isoda, H. Microarray analysis of verbenalin-treated human amniotic epithelial cells reveals therapeutic potential for Alzheimer's Disease. Aging 2020, 12, 5516-5538. [CrossRef] [PubMed]

9. Ferdousi, F.; Sasaki, K.; Ohkohchi, N.; Zheng, Y.-W.; Isoda, H. Exploring the Potential Role of Rosmarinic Acid in Neuronal Differentiation of Human Amnion Epithelial Cells by Microarray Gene Expression Profiling. Front. Neurosci. 2019, 13, 779. [CrossRef]

10. Uchida, Y.; Ferdousi, F.; Zheng, Y.-W.; Oda, T.; Isoda, H. Global Gene Expression Profiling Reveals Isorhamnetin Induces Hepatic-Lineage Specific Differentiation in Human Amniotic Epithelial Cells. Front. Cell Dev. Biol. 2020, 8, 578036. [CrossRef]

11. Bejaoui, M.; Ferdousi, F.; Zheng, Y.-W.; Oda, T.; Isoda, H. Regulating cell fate of human amnion epithelial cells using natural compounds: An example of enhanced neural and pigment differentiation by 3,4,5-tri-O-caffeoylquinic acid. Cell Commun. Signal. 2021, 19, 26. [CrossRef] [PubMed]

12. Khoo, H.E.; Azlan, A.; Tang, S.T.; Lim, S.M. Anthocyanidins and anthocyanins: Colored pigments as food, pharmaceutical ingredients, and the potential health benefits. Food Nutr. Res. 2017, 61, 1361779. [CrossRef] [PubMed]

13. Sytar, O.; Bośko, P.; Živčák, M.; Brestic, M.; Smetanska, I. Bioactive phytochemicals and antioxidant properties of the grains and sprouts of colored wheat genotypes. Molecules 2018, 23, 2282. [CrossRef]

14. Wu, X.; Pittman, H.E., 3rd; Prior, R.L. Fate of anthocyanins and antioxidant capacity in contents of the gastrointestinal tract of weanling pigs following black raspberry consumption. J. Agric. Food Chem. 2006, 54, 583-589. [CrossRef] [PubMed]

15. Azis, H.R.; Etteieb, S.; Takahashi, S.; Koshiyama, M.; Fujisawa, H.; Isoda, H. Effect of prohydrojasmon on total phenolic content, anthocyanin accumulation and antioxidant activity in komatsuna and lettuce. Biosci. Biotechnol. Biochem. 2020, 84, 178-186. [CrossRef] [PubMed]

16. Fimognari, C.; Berti, F.; Cantelli-Forti, G.; Hrelia, P. Effect of cyanidin 3-O-beta-glucopyranoside on micronucleus induction in cultured human lymphocytes by four different mutagens. Environ. Mol. Mutagen. 2004, 43, 45-52. [CrossRef] [PubMed]

17. Sorrenti, V.; Vanella, L.; Acquaviva, R.; Cardile, V.; Giofre, S.; Di Giacomo, C. Cyanidin induces apoptosis and differentiation in prostate cancer cells. Int. J. Oncol. 2015, 47, 1303-1310. [CrossRef]

18. Olivas-Aguirre, F.J.; Rodrigo-García, J.; Martínez-Ruiz, N.D.R.; Cárdenas-Robles, A.I.; Mendoza-Díaz, S.O.; Alvarez-Parrilla, E.; González-Aguilar, G.A.; De la Rosa, L.A.; Ramos-Jiménez, A.; Wall-Medrano, A. Cyanidin-3-O-glucoside: Physical-chemistry, foodomics and health effects. Molecules 2016, 21, 1264. [CrossRef]

19. Matsukawa, T.; Motojima, H.; Sato, Y.; Takahashi, S.; Villareal, M.O.; Isoda, H. Upregulation of skeletal muscle PGC-1 alpha through the elevation of cyclic AMP levels by Cyanidin-3-glucoside enhances exercise performance. Sci. Rep. $2017,7$.

20. Matsukawa, T.; Villareal, M.O.; Motojima, H.; Isoda, H. Increasing cAMP levels of preadipocytes by cyanidin-3-glucoside treatment induces the formation of beige phenotypes in 3T3-L1 adipocytes. J. Nutr. Biochem. 2017, 40, 77-85. [CrossRef]

21. Zhou, Z.; Nair, M.G.; Claycombe, K.J. Synergistic inhibition of interleukin-6 production in adipose stem cells by tart cherry anthocyanins and atorvastatin. Phytomedicine 2012, 19, 878-881. [CrossRef]

22. Miller, R.E.; Jones, J.C.; Tometsko, M.; Blake, M.L.; Dougall, W.C. RANKL Inhibition Blocks Osteolytic Lesions and Reduces Skeletal Tumor Burden in Models of Non-Small-Cell Lung Cancer Bone Metastases. J. Thorac. Oncol. 2014, 9, 345-354. [CrossRef] [PubMed]

23. Saulite, L.; Jekabsons, K.; Klavins, M.; Muceniece, R.; Riekstina, U. Effects of malvidin, cyanidin and delphinidin on human adipose mesenchymal stem cell differentiation into adipocytes, chondrocytes and osteocytes. Phytomedicine 2019, 53, 86-95. [CrossRef] [PubMed]

24. Cao, Y.; Gang, X.; Sun, C.; Wang, G. Mesenchymal Stem Cells Improve Healing of Diabetic Foot Ulcer. J. Diabetes Res. 2017, 2017, 9328347. [CrossRef] [PubMed]

25. Szwergold, B.S.; Howell, S.; Beisswenger, P.J. Human fructosamine-3-kinase: Purification, sequencing, substrate specificity, and evidence of activity in vivo. Diabetes 2001, 50, 2139-2147. [CrossRef] [PubMed]

26. Zheng, S.L.; Li, Z.Y.; Song, J.; Liu, J.M.; Miao, C.Y. Metrnl: A secreted protein with new emerging functions. Acta Pharmacol. Sin. 2016, 37, 571-579. [CrossRef]

27. Lindsay, A.J.; Jollivet, F.; Horgan, C.P.; Khan, A.R.; Raposo, G.; McCaffrey, M.W.; Goud, B. Identification and characterization of multiple novel Rab-myosin Va interactions. Mol. Biol. Cell 2013, 24, 3420-3434. [CrossRef]

28. Tsukamoto, K.; Sakaizumi, M.; Hata, M.; Sawara, Y.; Eah, J.; Kim, C.B.; Nonaka, M. Dichotomous haplotypic lineages of the immunoproteasome subunit genes, PSMB8 and PSMB10, in the MHC class I region of a Teleost Medaka, Oryzias latipes. Mol. Biol. Evol. 2009, 26, 769-781. [CrossRef]

29. Lim, C.M.; Cater, M.A.; Mercer, J.F.B.; La Fontaine, S. Copper-dependent interaction of glutaredoxin with the N termini of the copper-ATPases (ATP7A and ATP7B) defective in Menkes and Wilson diseases. Biochem. Bioph. Res. Commun. 2006, 348, 428-436. [CrossRef] 
30. Iio, A.; Takagi, T.; Miki, K.; Naoe, T.; Nakayama, A.; Akao, Y. DDX6 post-transcriptionally down-regulates miR-143/145 expression through host gene NCR143/145 in cancer cells. Bba Gene Regul. Mech. 2013, 1829, 1102-1110. [CrossRef] [PubMed]

31. Younis, S.; Kamel, W.; Falkeborn, T.; Wang, H.; Yu, D.; Daniels, R.; Essand, M.; Hinkula, J.; Akusjarvi, G.; Andersson, L. Multiple nuclear-replicating viruses require the stress-induced protein ZC3H11A for efficient growth. Proc. Natl. Acad. Sci. USA 2018, 115, E3808-E3816. [CrossRef] [PubMed]

32. Derunes, C.; Briknarova, K.; Geng, L.Q.; Li, S.; Gessner, C.R.; Hewitt, K.; Wu, S.D.; Huang, S.; Woods, V.I.; Ely, K.R. Characterization of the PR domain of RIZ1 histone methyltransferase. Biochem. Bioph. Res. Commun. 2005, 333, 925-934. [CrossRef]

33. Dou, C.; Li, J.; Kang, F.; Cao, Z.; Yang, X.; Jiang, H.; Yang, B.; Xiang, J.; Xu, J.; Dong, S. Dual Effect of Cyanidin on RANKL-Induced Differentiation and Fusion of Osteoclasts. J. Cell. Physiol. 2016, 231, 558-567. [CrossRef] [PubMed]

34. Rao, R.R.; Long, J.Z.; White, J.P.; Svensson, K.J.; Lou, J.; Lokurkar, I.; Jedrychowski, M.P.; Ruas, J.L.; Wrann, C.D.; Lo, J.C.; et al. Meteorin-like Is a Hormone that Regulates Immune-Adipose Interactions to Increase Beige Fat Thermogenesis. Cell 2014, 157, 1279-1291. [CrossRef] [PubMed]

35. Li, D.L.; Zhang, F.; Zhang, X.; Xue, C.Y.; Namwanje, M.; Fan, L.H.; Reilly, M.P.; Hu, F.; Qiang, L. Distinct functions of PPAR gamma isoforms in regulating adipocyte plasticity. Biochem. Bioph. Res. Commun. 2016, 481, 132-138. [CrossRef] [PubMed]

36. Fulda, S.; Gorman, A.M.; Hori, O.; Samali, A. Cellular Stress Responses: Cell Survival and Cell Death. Int. J. Cell Biol. 2010, 2010, 214074. [CrossRef] [PubMed]

37. Windahl, S.H.; Andersson, N.; Borjesson, A.E.; Swanson, C.; Svensson, J.; Moverare-Skrtic, S.; Sjogren, K.; Shao, R.; Lagerquist, M.K.; Ohlsson, C. Reduced bone mass and muscle strength in male 5alpha-reductase type 1 inactivated mice. PLoS ONE 2011, 6, e21402. [CrossRef] [PubMed]

38. Mansour, M.F.; Pelletier, M.; Tchernof, A. Characterization of 5 alpha-reductase activity and isoenzymes in human abdominal adipose tissues. J. Steroid. Biochem. 2016, 161, 45-53. [CrossRef]

39. Arimochi, H.; Sasaki, Y.; Kitamura, A.; Yasutomo, K. Differentiation of preadipocytes and mature adipocytes requires PSMB8. Sci. Rep. 2016, 6, 26791. [CrossRef]

40. Kakurina, G.V.; Kolegova, E.S.; Shashova, E.E.; Cheremisina, O.V.; Choynzonov, E.L.; Kondakova, I.V. Relationship between the mRNA Expression Levels of Calpains 1/2 and Proteins Involved in Cytoskeleton Remodeling. Acta Nat. 2020, 12, 110-113. [CrossRef]

41. Yang, W.; Guo, X.; Thein, S.; Xu, F.; Sugii, S.; Baas, P.W.; Radda, G.K.; Han, W. Regulation of adipogenesis by cytoskeleton remodelling is facilitated by acetyltransferase MEC-17-dependent acetylation of alpha-tubulin. Biochem. J. 2013, 449, 605-612. [CrossRef]

42. Marcon, B.H.; Rebelatto, C.K.; Cofre, A.R.; Dallagiovanna, B.; Correa, A. DDX6 Helicase Behavior and Protein Partners in Human Adipose Tissue-Derived Stem Cells during Early Adipogenesis and Osteogenesis. Int. J. Mol. Sci. 2020, 21, 2607. [CrossRef]

43. Manavalan, A.P.C.; Pilarova, K.; Kluge, M.; Bartholomeeusen, K.; Rajecky, M.; Oppelt, J.; Khirsariya, P.; Paruch, K.; Krejci, L.; Friedel, C.C.; et al. CDK12 controls G1/S progression by regulating RNAPII processivity at core DNA replication genes. EMBO Rep. 2019, 20, e47592.

44. Zhang, Y.F.; Jiang, R.; Li, J.D.; Zhang, X.Y.; Zhao, P.; He, M.; Zhang, H.Z.; Sun, L.P.; Shi, D.L.; Zhang, G.X.; et al. SMC1A knockdown induces growth suppression of human lung adenocarcinoma cells through G1/S cell cycle phase arrest and apoptosis pathways in vitro. Oncol. Lett. 2013, 5, 749-755. [CrossRef] [PubMed]

45. Ruijtenberg, S.; van den Heuvel, S. Coordinating cell proliferation and differentiation: Antagonism between cell cycle regulators and cell type-specific gene expression. Cell Cycle 2016, 15, 196-212. [CrossRef]

46. Kim, H.K.; Kim, J.N.; Han, S.N.; Nam, J.H.; Na, H.N.; Ha, T.J. Black soybean anthocyanins inhibit adipocyte differentiation in 3T3-L1 cells. Nutr. Res. 2012, 32, 770-777. [CrossRef] [PubMed]

47. Jeon, Y.; Lee, M.; Cheon, Y.P. A Testa Extract of Black Soybean (Glycine max (L.) Merr.) suppresses Adipogenic Activity of Adipose-derived Stem Cells. Dev. Reprod. 2015, 19, 235-242. [CrossRef] [PubMed]

48. Miki, T.; Strom, S.C. Amnion-derived pluripotent/multipotent stem cells. Stem Cell Rev. 2006, 2, 133-141. [CrossRef]

49. Jiawen, S.; Jianjun, Z.; Jiewen, D.; Dedong, Y.; Hongbo, Y.; Jun, S.; Xudong, W.; Shen, S.G.; Lihe, G. Osteogenic differentiation of human amniotic epithelial cells and its application in alveolar defect restoration. Stem Cells Transl. Med. 2014, 3, 1504-1513. [CrossRef]

50. Murphy, S.; Rosli, S.; Acharya, R.; Mathias, L.; Lim, R.; Wallace, E.; Jenkin, G. Amnion epithelial cell isolation and characterization for clinical use. Curr. Protoc. Stem. Cell Biol. 2010, 13, 1E.6.1-1E.6.25. [CrossRef]

51. Saito, S.; Yokoyama, K.; Tamagawa, T.; Ishiwata, I. Derivation and induction of the differentiation of animal ES cells as well as human pluripotent stem cells derived from fetal membrane. Hum. Cell 2005, 18, 135-141. [CrossRef] [PubMed]

52. Diaz-Prado, S.; Muinos-Lopez, E.; Hermida-Gomez, T.; Rendal-Vazquez, M.E.; Fuentes-Boquete, I.; de Toro, F.J.; Blanco, F.J. Multilineage Differentiation Potential of Cells Isolated From the Human Amniotic Membrane. J. Cell. Biochem. 2010, 111, 846-857. [CrossRef] [PubMed]

53. Gottipamula, S.; Sridhar, K.N. Large-scale Isolation, Expansion and Characterization of Human Amniotic Epithelial Cells. Int. J. Stem. Cells 2018, 11, 87. [CrossRef]

54. Huang, D.W.; Sherman, B.T.; Tan, Q.; Collins, J.R.; Alvord, W.G.; Roayaei, J.; Stephens, R.; Baseler, M.W.; Lane, H.C.; Lempicki, R.A. The DAVID Gene Functional Classification Tool: A novel biological module-centric algorithm to functionally analyze large gene lists. Genome Biol. 2007, 8, 1-16. [CrossRef] [PubMed] 
55. Huang, D.W.; Sherman, B.T.; Tan, Q.; Kir, J.; Liu, D.; Bryant, D.; Guo, Y.; Stephens, R.; Baseler, M.W.; Lane, H.C.; et al. DAVID Bioinformatics Resources: Expanded annotation database and novel algorithms to better extract biology from large gene lists. Nucleic Acids Res. 2007, 35, W169-W175. [CrossRef]

56. Takeuchi, T.; Noguchi, M.; Kawakami, Y.; Ohkohchi, N. Use of Human Biospecimen Resources for Drug Discovery-Approach of Tsukuba Human Tissue Biobank Center. Regul. Sci. Med. Prod. 2016, 6, 57-63.

57. Aonuma, K.; Ferdousi, F.; Xu, D.; Tominaga, K.; Isoda, H. Effects of isorhamnetin in human amniotic epithelial stem cells in vitro and its cardioprotective effects in vivo. Front. Cell Dev. Biol. 2020, 8, 578197. [CrossRef] 